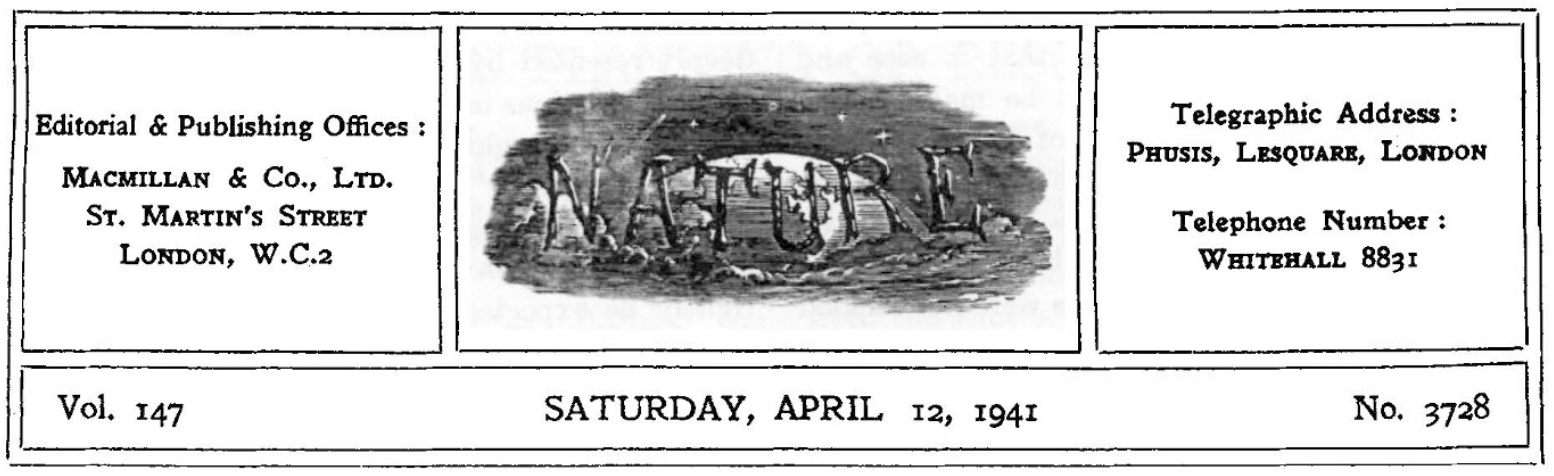

\title{
ASPECTS OF RECONSTRUCTION-II
}

A SPECIAL committee of the Town Planning Institute has been investigating the problem of compensation and betterment in relation to town planning*. A review of existing legislation on compensation and betterment and the acquisition of land by public authorities, including a survey of foreign practice, satisfied the Committee that essential planning, and particularly replanning, cannot be carried out effectively under the existing legislation, nor under any development of a system which involves the separate assessment of com. pensation and betterment in respect to each individual interest.

This Committee does not find that existing legislation is, in general, unjust to either private or public interests, although it recommends certain amendments which should mitigate some existing anomalies. The chief obstacle to the achievement of positive results by statutory planning is the multiplicity and variety of interests that hamper it on all sides, each of which has to be separately valued and taken into account. Consequently, where private ownerships present an obstacle to securing planned development, redevelopment or conservation on an economical basis, essential simplification and equity are likely to be best achieved by the wholesale purchase of areas by planning authorities. To facilitate this, the Committee recommends an amendment to the Town and Country Planning Act, giving powers to authorities to buy land required "for securing the preservation of existing buildings or other objects of architectural, historic or artistic interest or for the protection or improvement of agriculture". It is pointed out how essential it is that all publicly owned land should be subject to planning control under town

- Town and Country Planning: Compensation and Betterment. Pp. 60. (Town Planning Institute, 11 Arundel Street, London, W.C.2). and country planning schemes, and recommends that all land in the country should be planned and valued by one authority, on uniform principles and at one time, at intervals, for example, of five years, thus affording a datum time for the assessment of compensation or betterment.

These recommendations, the Committee considers, would secure rural preservation on a sound and fair economic basis, and check extravagant claims for schemes for the redevelopment of developed areas. It urges that creation of a National Planning Board with vested interests in development rights would be fatal, unless such rights were subject to planning control. It also recommends that land developers should be required, without compensation, to allocate not more than 35 per cent of the land for streets and open spaces, or instead to make a cash payment, such money to be used by the planning authority to provide open spaces in or adjacent to the land.

The Committee considers that mineral working is at present amply protected by the Town and Country Planning Act, but it strongly recommends that the owner should not be allowed to have the best of both worlds, but should be required to choose between mineral value and building value. It also proposes an amendment to secure that when surface minerals have been exploited no building value shall attach to the land, which will in consequence be available for open-space uses or for agriculture or afforestation at a value which makes such uses possible. It recommends the abolition of the disparity between compensation and betterment, and urges that the problem of the future will be to cope with the migration of population, not with its increase. The foundation of satellite towns would involve the occupation of compact areas of rural land, but in that case enough 
land should be purchased for the town and its agricultural belt, so that the question of claims for betterment would not arise.

The announcement that the Ministry of Works and Building has already set up an expert committee under Mr. Justice Uthwatt to examine the question of compensation and the recovery of betterment indicates that Lord Reith is already taking steps to deal with these problems. There is, in fact, already a wealth of material available for the assistance of the Minister of Works and Building, but even the most urgent demands for rebuilding require study and must conform to some plan if opportunities are not to be lost and fresh obstacles placed in the way of building more fitting and dignified cities where destruction has been concentrated. Unless at least the principles and outlines of an adequate plan are rapidly determined, there is grave danger that the necessity of physical rebuilding may in places jeopardize local if not national plans.

Scarcely less urgent are the second broad group of problems of reconstruction-what may be termed the rehabilitation problems. We shall be faced with the demobilization of large numbers of those in the armed and auxiliary forces and their return to peace-time employments. Industries that have swollen during the War to gigantic proportions will require relief from the troubles that may follow from surplus capacity. There will be other industries, which have had to close down during the War, to be restored to profitability. It would be optimistic indeed to assume that there will not be a new crop of depressed industries requiring care. Only foresight and careful investigation now can avoid severe dislocation and hardship when we begin to make the change-over from war to peace production.

There is no reason to be unduly pessimistic about our ability to surmount the difficulties with more success than last time, if forethought is given to the problems. The decline in our export trade, for example, which was such a stubborn element in our economic readjustment after 1918, is unlikely, in view of the much smaller part of export in our total economy to-day, to have the same effect on our general prosperity, even if it suffers as much. Moreover, we have advanced further in control of the trade cycle than we had in 1919. If we have a plan of campaign, we have a chance to control the post-War slump.

Overlapping with the remobilization of all our energies for the purposes of peaceful progress and orderly development are the problems involved in developing a new economic order and eliminating the frustration which has been responsible for the conditions leading up to the War, and removing the weaknesses which war has revealed. The development of our educational system and social services, the intensification of the attack on malnutrition and disease, the elimination of ugliness in our towns and replacement of the hovels that remain by worthy homes, demand creative thought as well as courage and determination to overcome whatever obstacles prejudice, vested interests, shortsightedness or ignorance may put in the way.

Success of such a policy and measures involves the fearless acceptance of the lessons of the War. No community can be exposed to such a strain as modern warfare imposes without some weak: nesses in structure or organization being exposed. Underlying the concern which has recently been expressed at the position of war-production is a growing realization of how completely unprepared for war our industry was, how grave a handicap we must always labour under if, after every war, we show such complete confidence in eternal peace. Whatever the size of the standing forces we find it advisable to maintain after the present War, we shall be blind indeed to the lessons of $1936-40$ if we do not maintain an embryo of munition industries, capable of rapid expansion, if we do not give all our citizens a minimum of training in their war-time duties, and if we do not make certain that stocks of the essential materials, adequately protected, are always kept in Great Rritain.

A further weakness which the War has revealed is the apparent failure to train up a sufficient supply of men of ability to lead the nation. The courage, skill and character of such sections of the nation as the pilots of the Royal Air Force suggest the question whether our peace-time social structure really takes the advantage it might of such men. The lack of ability at the top may be due to some defect or bottleneck in the system of selection, anc our educational system must be overhauled from the social point of view to determine whether it is at fault not so much on the pedagogical as on the social side.

Along with educational policy and system, national industrial policy requires overhaul. We have slipped from a laisser-faire system into one of State-encouraged cartels, not from deliberate choice but in a fit of absentmindedness. The pro. cess has been accentuated during the War by the policy of selecting the controllers, and economic 
reconstruction will be impossible unless we first examine the system to determine whether it is united to achieve that combination of progress with security that should be the economic objective of a dynamic democracy. If we are on the wrong road, the demobilization of war-time controls will offer us our last chance to change course.

These are only some of the major questions which the stress and strain of war have brought before us and to which answers are being urgently demanded. There are many others- the wide field of building the nation's health, the readjustment of town and country life, especially for children, forced upon us by evacuation, and the new conception of colonial responsibilities to which the White Paper of a year ago gave expression. Here will be found the fields for Mr. Greenwood to plan in advance, as Mr. Churehill said in the recent debate, "a number of lárge practical steps which it is indispensable to take if our society is to move forward". The immensity of the task should be an inspiration and not a deterrent. The intensity of our concentration at the moment on the full utilization and proper distribution of the powers of production is providing us with the power to realize such plans when hostilities terminate. The expansion of industry dictated by the requirements of war is already, by the problems it creates, shaping the plan of future reconstruction. If that plan is worked out and set in motion, it will eventually, with the minimum of friction and delay, absorb the resources of production which will be released when the War comes to an end.

If therefore the call is to hard thinking and concrete planning, to the devising of appropriate machinery, drawing on the widest and wisest experience and ablest minds of the nation, it is equally one to co-operation. Mr. Churchill's plea for a continuance of national and political unity during the period immediately after the War is a sign that the Government is thinking ahead. Already it is becoming widely realized that the end of the War will be a signal, not to return to idleness and complacency, but to undertake great things. If that call is heeded, if professional men unite to bring a spirit of disinterested service, impartial inquiry and constructive thought into all those fields where their special knowledge or experience is of service, we need not despair of our ability to relieve distress and bridge the gap between war and peace, and to organize that full employment of resources which can both repair the ravages of war and usher in an ampler and nobler world order worthy of the sacrifices now being made.

\section{RELATIONSHIP OF PURE AND APPLIED BIOLOGY}

$\mathrm{T}$ $\mathrm{HE}$ great number and the immediacy of applied biological problems in this time of war, coupled with the embarrassingly small use made of pure biologists by those in authority, has raised acutely the problem of the relationship of pure and applied biology*. To a certain extent academic botanists and zoologists are themselves to blame for their apparent uselessness, since for long they have tended to hold themselves aloof from applied work and have, indeed, sometimes decried not only its intellectual status but even its scientific value.

This superficial and arbitrary division of biology into 'pure' and 'applied' is a very unfortunate development of comparatively recent times. For Robert Boyle, true science was such knowledge

* Discussed at a joint meeting of the Association of Applied Biologists and the Society for Experimental Biology on Friday, March 28,1941 . The opening addresses were given by Prof. P. A. Buxton and Prof. W. B. Brierley. See also pp. 436 and 439 of this issue. "as hath a tendency to use", and for Francis Bacon "such philosophy as . . . shall be operative to the endowment and betterment of man's life". So recently as the days of Pasteur there was neither 'pure' nor 'applied'; there was simply biology, botanists and zoologists increasing knowledge and adding to the sum of human welfare. But in the thirty years or so overlapping the birth of this century, a series of trends and conditions, which in themselves make a fascinating history, led to the professionalization of biology; by the early 1900's most university professors had become 'pure' biologists, and by the 1920's they had become narrow specialists in one or another branch of pure biology. Such a condition was, clearly, far from satisfactory.

So artificial, so one-sided and extreme was this development, that it stimulated a reactive movement. In 1904 the Association of Applied Bio- 